\title{
Chondroid metaplasia: a rare subtype of metaplastic breast carcinoma
}

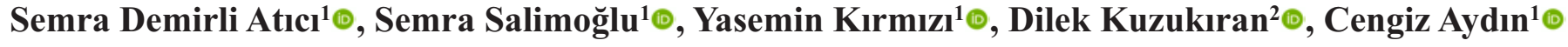

${ }^{1}$ Department of General Surgery, University of Health Sciences, Tepecik Training and Research Hospital, İzmir, Turkey

${ }^{2}$ Department of General Surgery, Tatvan State Hospital, Bitlis, Turkey

\begin{abstract}
Metaplastic breast carcinoma (MBC) is a subtype of breast malignant lesions which is very rare seen. Clinically, $\mathrm{MBC}$ is more aggressive and has worse prognosis than other subtypes of breast cancers. A 61-year-old female patient who had a rapidly enlarging and palpabl mass on the left breast applied. Core biopsy was performed and pathology was reported as invasive ductal carcinoma. The patient who had been diagnosed with breast cancer was operated and postoperative course was unremarkable. She was discharged postoperative third day with no complication. Postoperative specimen pathology was reported as a rare type of breast metaplastic carcinoma which was chondroid metaplasia. Here we aimed to report, a case of chondroid metaplasia which is a rare type of metaplastic breast carcinoma with the literature.

Keywords: Metaplastic carcinoma, chondroid metaplasia, breast cancer
\end{abstract}

M etaplastic breast carcinoma is rare seen among the breast malignant lesions [1]. 1-2\% of malignant breast lesions was determined as $\operatorname{MBC}[2,3]$. Metaplastic breast carcinoma has both epithelial and mesenchymal malignant tissue components. According to the components they contain, metaplastic breast carcinoma has five subtypes. According to the 2012 WHO classification; low grade adenosquamous carcinoma,fibromatous-like metaplastic carcinoma, squamous cell carcinoma, spindle cell carcinoma, mesenchymal differentiation carcinoma (chondroid differentiation, osseous differentiation and other mesenchymal differentiation types) [4]. Clinically, MBC is more aggressive and had a shorter overall survival than other subtypes of breast malignencies. MBC had a worse prognosis due to present with a larger tumor size which were mostly undifferentiated type and involvement of less lymph nodes, which are usually triple negative [3-5]. Although the management of MBC was essentially similar to invasive ductal carcinoma, there is no specificizied treatment approach for MBC management [3, 6, 7].

\section{CASE PRESENTATION}

A 61-year-old female patient presented with a complaint of a rapidly growing, painless mass on the left breast, covering almost all of the breast. Breast ultrasonography showed a $6 \times 6 \mathrm{~cm}$ solide lobular contoured lesion with heterogeneous calcifications and acoustic shade which located in left breast lower middle zone. In thorax computed tomographic imaging, in the left breast there was a $63 \times 55 \mathrm{~mm}$ irregular contoured mass containing calcifications, and thickening of the breast skin and subcutaneous tissues 


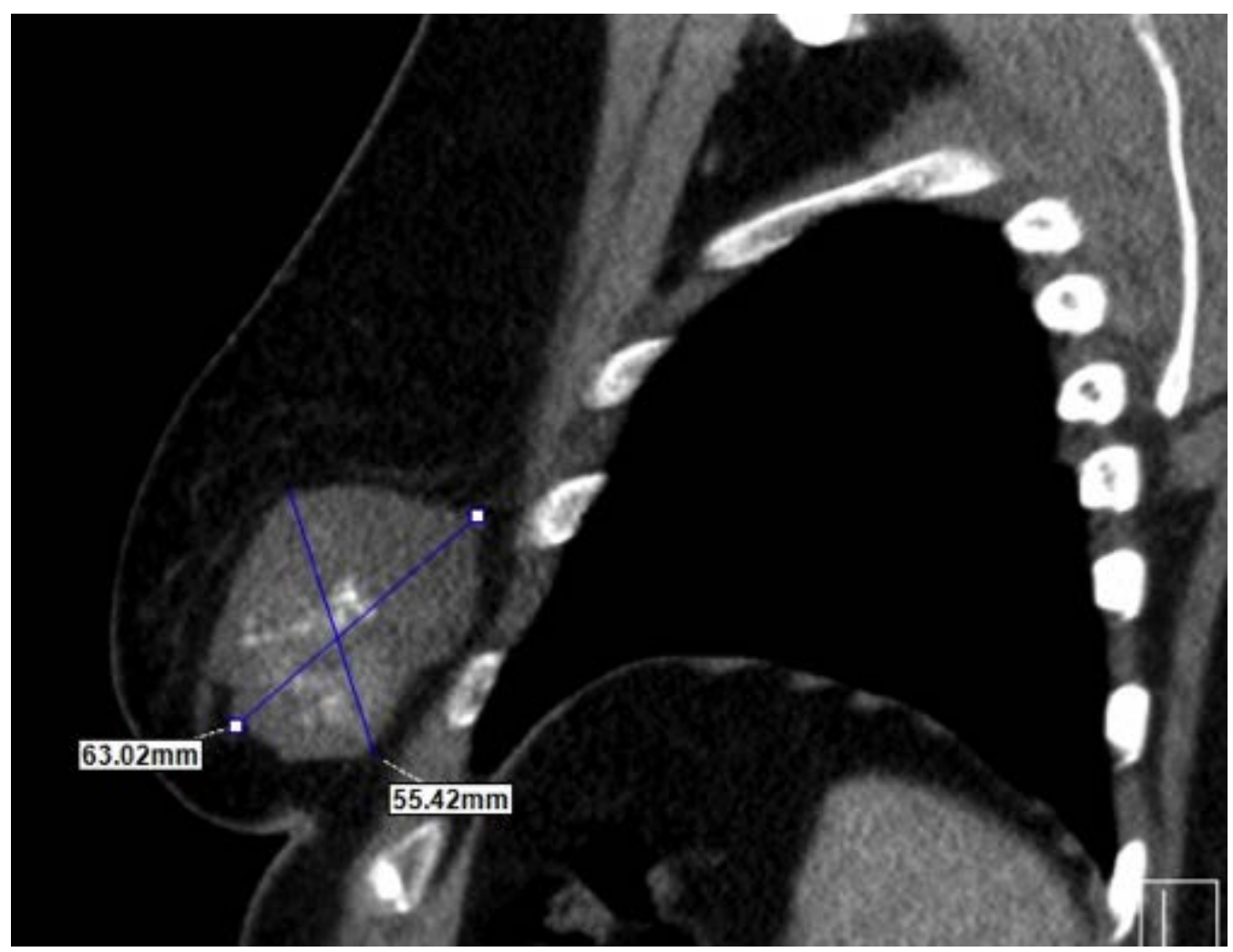

Fig. 1. Thorax CT imaging shows a $63 \times 55 \mathrm{~mm}$ irregular contoured mass containing calcifications, and thickening of the breast skin and subcutaneous tissues in the left breast.

(Fig. 1). Core biopsy was performed. Pathology showed invasive ductal carcinoma with ER 40\% (+), PR (-), Ki67: 20\%, CerB2: (-), E-cadherin: (+). No distant metastases were observed in the preoperative imaging methods. Written informed consent form was obtained for patient treatment, surgery and publication. Peroperative sentinel lymph node biopsy (SLNB) was performed. Axillary dissection was not performed upon arrival as a frozen of SLNB reported as reactive lymphadenopathy. Left mastectomy was performed because of mass that covers almost all of the breast. Postoperative course was unremarkable. Postoperative third day.hemovac dren was taken and she was discharged wiith no complication. Postoperative specimen pathology was competiable with a rare subtype of metaplastic breast carcinoma, as chondroid metaplasia. The histopathological examination showed; ER 40\% (+), PR 20\% (+), Ki67: 40\%, CerB2: (-), E-cadherin: (+) with a size of $6 \times 5 \times 4 \mathrm{~cm}$ tumor which located lower middle zone of breast, with free tumor on surgical margin.

The patient was referred to the department of medical oncology further postoperative treatment.
Patient receiving adjuvant chemotherapy, without recurrence at postoperative 25 th month are followed.

\section{DISCUSSION}

Metaplastic breast carcinoma which has epithelial and mesenchymal malignant tissue components, is generally presented rapidly growing masses. MBC is aggresive, generally had a poor prognosis and had a high grade, with a propensity for recurrence $[2,3]$. Preooperative radiological findings has similarity to other malign breast lesions. Radiological findings may be varied according to tumor components [3]. MBC is mostly seen in the fifth decades, and generally come up with fast-growing large-sized masses in short time intervals [2]. It has been determined that the tumor size can be changed in the range of 1.4-14.8 cm with the studies $[3,8]$.

In the majority of studies performed, it was found that hormone receptors, which is another factor that affects the treatment of metaplastic breast cancer, are negative $[2,3,6]$. Due to that, hormonal therapy 
largely has no role in these patients with $\mathrm{MBC}$. Cimino-Mathews et al. [8] found 20\% ER/PR positive, $9 \%$ HER-2 positive, and $69 \%$ triple negative in their study which involving 45 patients with metastatic breast carcinoma. Despite the large size of tumors in MBC lymph node involvement is less seen than adenocarcinoma $[3,5,6]$. The incidence of lymph node metastasis can be change between $0-63 \%$ [5]. When patients diagnosed with MBC disease stage generally tends to be higher in stage than in invasive carcinoma and also prognosis of metaplastic carcinoma is worse than invasive carcinoma [6]. Important in determining the prognosis is the type and prevalence of the metaplastic component such as tumors with sarcomatous component have been reported to have a worse prognosis. [7]. However, 5year survival rate reported with metaplastic carcinoma chondroid or osseous metaplasia is $20-68 \%$ and also $19-25 \%$ axillary lymph node metastasis, $21 \%$ distant metastasis [4]. Optimal treatment strategies for metaplastic breast cancer are still unclear. There is no standard adjuvant therapy for MBC. Chemotherapy shows lower response rates than other basal-like tumors in $\mathrm{MBC}$ which generally has negative for estrogen receptor, progesterone receptor and HER-2 negative [3]. However, the neoadjuvant chemotherapy (NAC) for MBC is not well defined, we know that the role of NAC has expanded from its use in infammatory and locally advanced tumors to patients with early stage breast cancer. Al Hilli et al [9] reported that $\mathrm{MBC}$ had a poorly responsive to NAC. However, Tseng and Martinez [10] and PaulWright et al. [11] suggested that administration of radiotherapy is associated to improved survival in MBC.

MBC with presenting fast grow lump, studies suggesting mastectomy or modified radical mastectomy (MRM) rather than lumpectomy $[3,6,7]$. However, there are publications showing no contribution to survival for breast conserving surgery or mastectomy $[3,10]$. MRM or mastectomy is preferable to in breast conservation surgery (BCS); because of the possibility of local recurrence between $35-62 \%$ within the first $2-5$ years [12].

\section{CONCLUSION}

$\mathrm{MBC}$ breast carcinoma is a rare seen type of breast cancer which presented with rapidly growing palpable masses, although the rate of lymph node metastasis is low. Because of the higher risk of local recurrence in $\mathrm{MBC}, \mathrm{MRM}$ or mastectomy is generally preferred to BCS for surgical treatment. Considering poor prognosis and decreased response to treatment for MBC, new treatment modalities should be identified.

\section{Informed consent}

Written informed consent was obtained from the patient for publication of this case report and any accompanying images.

\section{Conflict of interest}

The authors declared that there are no potential conflicts of interest with respect to the research, authorship, and/or publication of this article.

\section{Acknowledgement}

This case report has been presented as a poster presentation at 21th National Surgical Congress, April 11-15, 2018, Antalya, Turkey

\section{REFERENCES}

1. Beatty JD, Atwood M, Tickman R, Reiner M. Metaplastic breast cancer: clinical significance. Am J Surg 2006;191:657-64. 2. Nelson AR, Guye ML, Luu T, Lai LL. Survival outcomes of metaplastic breast cancer patients: results from a US populationbased analysis. Ann Surg Oncol 2015;22:24-31.

3. Salimoğlu S, Sert İ, Emiroğlu M, Karaali C, Kuzukıran D, Akyüz Kırmızı Y, et al. Metaplastic breast carcinoma: analysis of clinical and pathologic characteristics. J Breast Health 2016;12: 63-6.

4. Lakhani SR, Ellise IO, Schnitt SJ, Tan PH, van de Vijver MJ. editors. WHO classification of tumors of the breast. 4th ed. Lyon, France: IARC; 2012: p85-7.

5. Luini A, Aguilar M, Gatti G, Fasani R, Botteri E, Brito JA, et al. Metaplastic carcinoma of the breast, an unusual disease with worse prognosis: the experience of the European Institute of Oncology and review of the literature. Breast Cancer Res Treat 2007;101:349-53.

6. Pezzi CM, Patel-Parekh L, Cole K, Franko J, Klimberg VS, Bland K. Characteristics and treatment of metaplastic breast cancer: analysis of 892 cases from the national cancer data base. Ann Surg Oncol 2007;14:166-73.

7. Al Sayed AD, El Weshi AN, Tulbah AM, Rahal MM, Ezzat AA. Metaplastic carcinoma of the breast clinical presentation, treatment results and prognosis factors. Acta Oncol 2006;45:18895.

8. Cimino-Mathews A, Verma S, Figueroa-Magalhaes MC, Jeter 
SC, Zhang Z, Argani P, et al. A clinicopathologic analysis of 45 patients with metaplastic breast carcinoma. Am J Clin Pathol 2016;145:365-72.

9. Al-Hilli Z, Choong G, Keeney MG, Visscher DW, Ingle JN, Goetz MP, et al. Metaplastic breast cancer has a poor response to neoadjuvant systemic therapy. Breast Cancer Res Treat 2019;176:709-16.

10. Tseng WH, Martinez SR. Metaplastic breast cancer: to radiate or not to radiate? Ann Surg Oncol 2011;18:94-103.
11. PaulWright G, Davis AT, Koehler TJ, Melnik MK, Chung $\mathrm{MH}$. Hormone receptor status does not affect prognosis in metaplastic breast cancer: a population-based analysis with comparison to infiltrating ductal and lobular carcinomas. Ann Surg Oncol. 2014;21:3497-503.

12. Tașdemir A, Oğuz A, Ünal D, Tuna Ö. Metaplastic carcinoma of the breast: a rare carcinoma with chondroid metaplasia. Ulusal Cer Derg 2014;30:57-9. 